\title{
Changes in Sugar, Titratable Acidity, and Ascorbic Acid Content during Fruit Development in Sea Buckthorn (Hippophae rhamnoides L.)
}

\author{
Wataru Ohkawa ${ }^{1}$, Yoshinori Kanayama ${ }^{1 *}$, Emi Chiba $^{1}$, Katja Tiitinen ${ }^{2}$ and Koki Kanahama ${ }^{1}$ \\ ${ }^{1}$ Graduate School of Agricultural Science, Tohoku University, Sendai 981-8555, Japan \\ ${ }^{2}$ Department of Biochemistry and Food Chemistry, University of Turku, 20014 Turku, Finland
}

\begin{abstract}
We compared the changes of sugar content and titratable acidity throughout fruit development in two cultivars, 'Russian Orange' from subspecies (ssp.) mongolica and 'Hergo' from ssp. rhamnoides of sea buckthorn (Hippophae rhamnoides L.). In 'Russian Orange' fruit, glucose content increased remarkably from mid-July to early August, whereas the contents of fructose, sucrose and ethylglucose did not increase. In 'Hergo' fruit, the content of each sugar did not increase during fruit development. Fruit titratable acidity was low during early fruit development, then remarkably increased from mid-July to early August and decreased at harvesting time in both cultivars. The sugar/acid ratio in ripe fruit was 1.14 in 'Russian Orange' and 0.34 in 'Hergo', indicating that 'Russian Orange' fruit has better flavor. In tracer experiments using ${ }^{14} \mathrm{CO}_{2},{ }^{14} \mathrm{C}$-sucrose was found to be the major sugar in the leaves and the stems, suggesting that sucrose is the primary product of photosynthate and a translocatable sugar in sea buckthorn plants. Ascorbic acid content in 'Russian Orange' fruit decreased during fruit development, while the content in 'Hergo' fruit was roughly constant. 'Russian Orange' fruit showed high Lgalactose dehydrogenase (L-GDH) activity. In tracer experiments, ${ }^{14} \mathrm{C}$-ascorbic acid was synthesized from $\mathrm{L}-{ }^{14} \mathrm{C}$ galactose and $\mathrm{D}^{14} \mathrm{C}$-mannose. These results suggest that the mannose/L-galactose pathway plays a role in the synthesis of ascorbic acid in sea buckthorn fruit.
\end{abstract}

Key Words: ascorbic acid, L-galactose dehydrogenase, sea buckthorn, sugar, titratable acidity.

\section{Introduction}

Sea buckthorn (Hippophae rhamnoides L.) of the family Elaeagnaceae is a deciduous and dioecious small fruit tree with thorny branches that is widely distributed in Europe and Asia. This species comprises several subspecies (spp.), including the ssp. rhamnoides, which is distributed in the North Sea and the Baltic coast, the ssp. mongolica of Mongolia and Siberia, and the ssp. sinensis of China (Kanahama, 2004). Sea buckthorn is a stress-tolerant (Li et al., 2005; Yang et al., 2005) and actinorhizal plant that is infected with Frankia, an actinomycetic endophyte of woody trees and shrubs, for the formation of root nodules that fix nitrogen (Gentili and Huss-Danell, 2002; Kato et al., 2007). These characteristics could facilitate cultivation in poor environments where it is difficult to grow other species. Recently, in Japan, the cultivation of sea buckthorn was attempted in mountainous areas, where other cultivation

Received; August 20, 2008. Accepted; December 18, 2008

* Corresponding author (E-mail: kanayama@bios.tohoku.ac.jp). efforts had been abandoned (Kanahama, 2004).

Since sea buckthorn fruit are rich in tocopherols (Kallio et al., 2002), unsaturated fatty acids (Yang and Kallio, 2002) and phenol compounds (Gao et al., 2000), they have been used for food and medicinal purposes. Because of its nutritional components and nitrogenfixation ability, sea buckthorn may also be useful for ensuring food sefety and sustainable production (Kanayama et al., 2008). The cultivation of sea buckthorn is therefore expected to be developed for various purposes.

Tang et al. (2001) reported that increasing the sugar/ acid ratio is an important factor in improving the flavor of sea buckthorn fruit, because sea buckthorn fruit have low sugar content and high titratable acidity (Rongsen, 2006). Glucose and fructose are reportedly the main sugars in ripe fruit while sucrose content is low (Tang and Tigerstedt, 2001). Sea buckthorn fruit also contain a unique glucose derivative, ethylglucose (Tiitinen et al., 2006). The main organic acids in the fruit are reportedly malic acid and quinic acid (Raffo et al., 2004; Tiitinen et al., 2006). Most previous studies have focused on 
sugar and acid contents in ripe fruit or its juice in terms of food chemistry; however, information is lacking on changes in the content of sugars and organic acids throughout fruit development, especially during early fruit development. There is also less information about translocatable sugars in sea buckthorn.

Ascorbic acid has diverse roles in plant metabolism and is also important as vitamin $\mathrm{C}$ for humans, who are unable to synthesize this vitamin by themselves. Ascorbic acid content in sea buckthorn fruit is known to be high compared to that in other fruit crops (Agius et al., 2003; Richardson et al., 2004). Recently, some pathways for ascorbic acid biosynthesis have become clear in plants (Wheeler et al., 1998), whereas in sea buckthorn fruit, the ascorbic acid synthetic pathway is still unknown.

Physiological and biochemical studies throughout fruit development are necessary to improve fruit quality involving sugars and organic acids. Although Raffo et al. (2004) and Tang (2002) reported changes in sugar and organic acid content during fruit maturation, they did not measure sucrose and ethylglucose content; therefore, in this experiment, we compared the changes in the content of sugars, which are not only hexose but also sucrose and ethylglucose, and titratable acidity throughout fruit development in two cultivars of ssp. mongolica (Russian origin) and ssp. rhamnoides (European origin), whose cultivation has recently extended to Canada and the USA (Letchamo et al., 2007). In addition, we examined the metabolic pathway of ascorbic acid in sea buckthorn plants.

\section{Materials and Methods}

\section{Plant materials}

Four-year-old trees of sea buckthorn (H. rhamnoides ssp. mongolica 'Russian Orange' and ssp. rhamnoides 'Hergo') from rooted cuttings were grown in the field of the Graduate School of Agricultural Science, Tohoku University. Popular cultivars were used from two subspecies to investigate of divergent characteristics in sea buckthorn. More than hundred fruit were collected at random from immature to optimally ripe stages from three individual trees. Ten fruit from each tree were weighed. The collected fruit were frozen in liquid nitrogen and stored at $-80^{\circ} \mathrm{C}$ until use.

Determination of sugar, organic acid, and ascorbic acid

Soluble carbohydrates were extracted in hot $80 \%$ (v/ v) ethanol and determined using HPLC equipped with a refractive-index detector, as described by Suzuki et al. (2001). Titratable acidity was determined using $0.1 \mathrm{~N}$ $\mathrm{NaOH}$ and expressed as malic acid equivalents.

Ascorbic acid was extracted with $1.5 \% \quad(\mathrm{w} / \mathrm{v})$ metaphosphoric acid and filtered through filter paper (Lorence et al., 2004). The filtrate was adjusted to pH 3.5-4.0 with $\mathrm{KOH}$ and subjected to enzymatic determination of ascorbic acid using an F-Kit (JK
International, Tokyo, Japan), in which ascorbate oxidase is used for the determination, according to the manufacture's instructions.

Tracer experiments of translocatable sugar and ascorbic acid biosynthesis, and determination of L-galactose dehydrogenase (L-GDH) activity

Based on the method of Ohkawa et al. (2007), $0.37 \mathrm{MBq}$ of ${ }^{14} \mathrm{CO}_{2}$ was fed to a detached shoot of 'Russian Orange' for one hour in early September. Twenty-four hours after the start of ${ }^{14} \mathrm{CO}_{2}$ feeding, soluble carbohydrates were extracted from the ${ }^{14} \mathrm{CO}_{2}$ fed leaf and stem in hot $80 \%(\mathrm{v} / \mathrm{v})$ ethanol. ${ }^{14} \mathrm{C}$-sugars were determined using HPLC equipped with a radioactive flow-through monitor and a refractive-index detector. Five independent experiments were carried out using the three trees described above.

In early July, $18.5 \mathrm{kBq}$ of ${ }^{14} \mathrm{C}$-glucose, $\mathrm{L}-{ }^{14} \mathrm{C}$-galactose or ${ }^{14} \mathrm{C}$-mannose was fed to the peduncle of detached 'Russian Orange' fruit. The ${ }^{14} \mathrm{C}$-sugars were placed in cylindrical holes of $3.4 \mathrm{~mm}$ in the diameter on a plastic board and fruit were placed on these holes to soak the peduncle in the ${ }^{14} \mathrm{C}$-sugars. Eighty hours after the start of ${ }^{14} \mathrm{C}$-sugar feeding, ascorbic acid, galactose, and mannose were extracted with $1.5 \%(\mathrm{w} / \mathrm{v})$ metaphosphoric acid and determined using HPLC equipped with a radioactive flow-through monitor and a UV/VIS detector.

L-GDH was extracted from 'Russian Orange' fruit sampled on August 8 and 14 as described previously (Wheeler et al., 1998). The extract was used after desalting for the assay of enzyme activity by following $\mathrm{NADH}$ formation at $340 \mathrm{~nm}$ (Wheeler et al., 1998).

\section{Results and Discussion}

Fruit weight, sugar content, and titratable acidity

The fruit weight of 'Russian Orange' rapidly increased during fruit development, and the fruit was suitable to harvest on August 8 to 15 (Fig. 1). The fruit weight of 'Hergo' showed a slower increase than 'Russian Orange' up to mid-September, and the fruit ripened on September

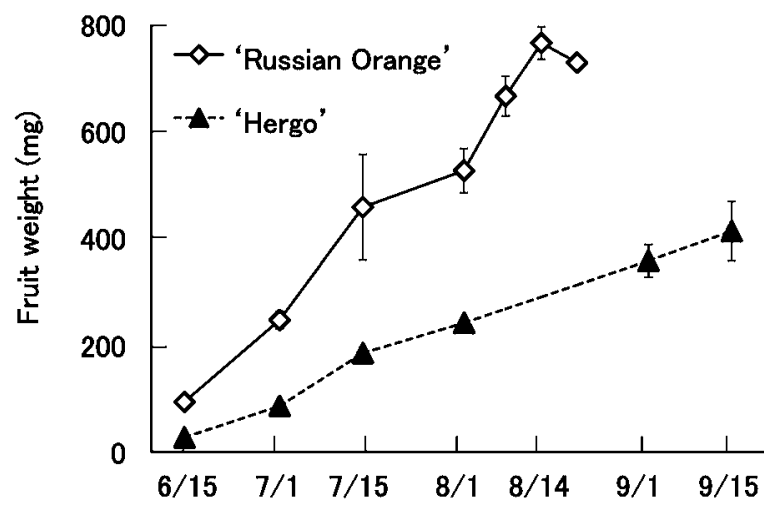

Fig. 1. Seasonal changes in fruit weight in sea buckthorn. Vertical bars indicate SE $(n=3)$. 
15. Fruit ripening was judged by fruit softening and skin color. At harvest time, the weight per fruit of 'Russian Orange' was approximately $650 \mathrm{mg}$ and that of 'Hergo' was approximately $400 \mathrm{mg}$. Raffo et al. (2004) reported that the fruit weight was $300 \mathrm{mg}$ in 'Hergo' grown in Rome, Italy. Although 'Hergo' fruit was much smaller in this study than in Raffo et al. (2004) in mid-June, the fruit weight thereafter increased more rapidly in this study, suggesting better environmental conditions for fruit growth from July to September in Sendai, Japan.

In 'Russian Orange' fruit, the glucose content increased remarkably from mid-July to early August, while the contents of fructose, sucrose, and ethylglucose did not increase throughout fruit development (Fig. 2). At harvest time, total sugar content was approximately $20 \mathrm{mg} \cdot \mathrm{g}^{-1} \mathrm{FW}$ and glucose content was approximately $60 \%$ of total sugar content. In 'Hergo' fruit, the content of each sugar did not increase during fruit development. At harvest time, total sugar content was approximately $13 \mathrm{mg} \cdot \mathrm{g}^{-1} \mathrm{FW}$ and glucose content was approximately $30 \%$ of total sugar content. Tiitinen et al. (2006) reported that ethylglucose content is negatively correlated with glucose content in spp. mongolica and spp. rhamonoides. In this study, although the ethylglucose contents were similar in the two cultivars, the glucose content in 'Russian Orange' fruit was much higher than that in 'Hergo' fruit. Thus, ethylglucose content is not always a determinant of glucose content. Tang (2002) stated
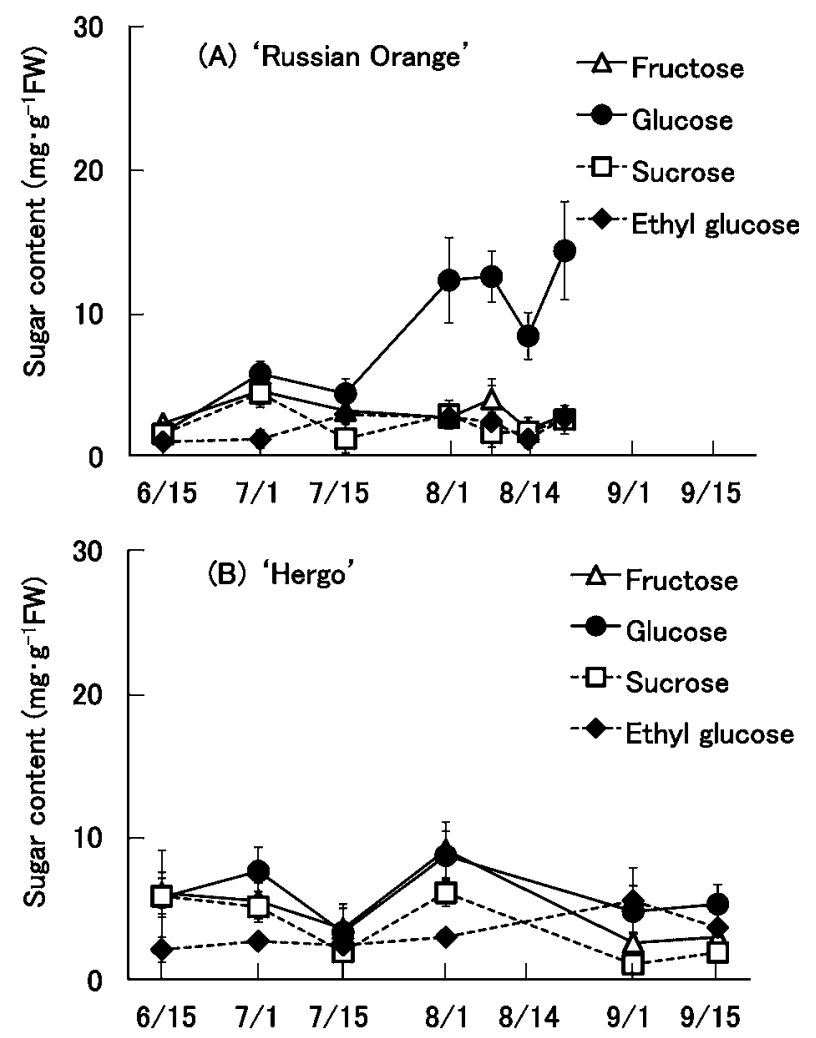

Fig. 2. Seasonal changes in sugar content in sea buckthorn fruit. A: ssp. mongolica 'Russian Orange', B: ssp. rhamnoides 'Hergo'. Vertical bars indicate SE $(n=3)$. that sucrose content is much lower than fructose content without showing any data; however, sucrose content was similar to fructose content in this study (Fig. 2).

Raffo et al. (2004) reported that fruit organic acid content in three cultivars of ssp. rhamnoides decreased with fruit ripening from August to September. To our knowledge, there is no report about fruit acid content from early fruit development. In this study, titratable acidity was low during early fruit development, and then marked increased from mid-July to early August in both cultivars (Fig. 3). At harvesting time, titratable acidity had decreased to $16 \mathrm{mg} \cdot \mathrm{g}^{-1} \mathrm{FW}$ in 'Russian Orange' and $31 \mathrm{mg} \cdot \mathrm{g}^{-1} \mathrm{FW}$ in 'Hergo'. This change in titratable acidity is similar to that in grape berries, although the titratable acidity is lower in grape berries (Matsui et al., 1979). Since a decrease in the titratable acidity corresponds to an increase in reducing sugar content in grape berries around 4 weeks before ripening, Matsui et al. (1979) suggested the conversion of organic acids into reducing sugars; however, this is not the case in 'Russian Orange' fruit, in which the titratable acidity rather increased with glucose content (Figs. 2 and 3).

The results of sugar content and titratable acidity showed different fruit characteristics between the two cultivars, that is, higher sugar content and lower acidity in 'Russian Orange' fruit. The sugar/acid ratio in ripe fruit was 1.14 in 'Russian Orange' and 0.34 in 'Hergo', indicating that 'Russian Orange' fruit has better flavor. Comparatively low sugar/acid ratios in spp. rhamnoides were also observed in previous studies (Raffo et al., 2004; Tang, 2002). Although the sugar/acid ratio in sea buckthorn is much lower than in most other fruit crops, that in 'Russian Orange' with better flavor is higher than in lemon and lime (Albertini et al., 2006).

Although decreasing organic acid content is important for improving fruit flavor, the sugar content and sugar composition should also be improved. Interestingly, quite different developmental patterns of sugar accumulation in fruit were observed between the two cultivars. The divergent accumulation mechanisms for sugars are mainly due to glucose accumulation in the late stage of fruit development, which was observed not in spp.

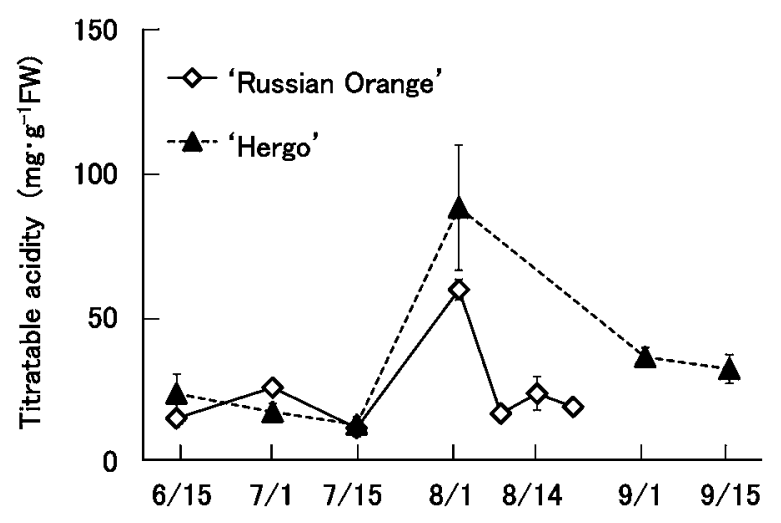

Fig. 3. Seasonal changes in titratable acidity in sea buckthorn fruit. Vertical bars indicate SE $(n=3)$. 
rhamonoides but in spp. sinensis in the previous studies (Raffo et al., 2004; Tang, 2002); however, glucose increases with fructose in the genotype of ssp. sinensis (Tang, 2002), unlike 'Russian Orange'. Since fruit species that specifically accumulate glucose, such as 'Russian Orange' are rare, sea buckthorn is also useful to investigate of glucose accumulation in fruit.

Because fructose is twice as sweet as glucose, increasing fructose content might have an impact on improving the fruit flavor. Some cultivars accumulate fructose as well as glucose in ripe fruit (Tiitinen et al., 2006). In addition to the characteristic of glucose accumulation, that of fructose accumulation would be useful in sea buckthorn fruit. High soluble solids content in the fruit of wild tomato species are related to sucrose accumulation, whereas hexose accumulates in the fruit of cultivated tomato species that show low soluble solids content (Yelle et al., 1988); therefore, increasing the sucrose content possibly results in a high soluble solids content. Sundriyal and Sundriyal (2004) found that sucrose content is similar to glucose content in the fruit of Himalayan wild sea buckthorn plants. A difference in sugar metabolism between fructose or sucrose accumulators and glucose accumulators should be investigated.

\section{Translocatable sugar in sea buckthorn plants}

The metabolism of translocatable sugars in fruit is important for fruit quality. In tomato fruit, cell-wall invertase, which first hydrolyzes a translocatable sugar, sucrose, plays a key role in sugar accumulation in fruit (Fridman et al., 2004); however, translocatable sugar differs in plant species. In melon plants, in which photosynthates are translocated as raffinose family oligosaccharides (RFOs), alpha-galactosidase, which hydrolyzes RFOs, has been investigated (Gao and Schaffer, 1999). In Rosaceae fruit trees, in which photosynthates are translocated as sorbitol, NADdependent sorbitol dehydrogenase may play a role in sugar accumulation into fruit (Kanayama et al., 2005; Yamada et al., 2001). There is less information about translocatable sugars in small fruit trees, including sea buckthorn. Thus, we carried out tracer experiments using ${ }^{14} \mathrm{CO}_{2}$. As described in Table $1,{ }^{14} \mathrm{C}$-sucrose was found to be a major sugar in the leaves and stems of 'Russian Orange' at approximately 70 and $86 \%$ of the total ${ }^{14} \mathrm{C}$ sugars, respectively. This result suggests that sucrose is the primary product of photosynthate and is a translocatable sugar in sea buckthorn plants.

Table 1. ${ }^{14} \mathrm{C}$ distribution to each sugar (\%) in leaves and stems in sea buckthorn $23 \mathrm{~h}$ after ${ }^{14} \mathrm{CO}_{2}$ feeding for $1 \mathrm{~h}$.

\begin{tabular}{lcrc}
\hline \hline & Fructose & Glucose & Sucrose \\
\hline Leaf & $17.0 \pm 2.7^{\mathrm{z}}$ & $12.8 \pm 1.8$ & $70.2 \pm 3.0$ \\
Stem & $6.9 \pm 4.0$ & $7.1 \pm 1.0$ & $86.0 \pm 9.9$ \\
\hline
\end{tabular}

${ }^{\mathrm{z}} \operatorname{Mean} \pm \operatorname{SE}(\mathrm{n}=5)$.
Ascorbic acid content and its metabolism

Sea buckthorn fruit showed divergent patterns of ascorbic acid accumulation as well as sugar accumulation. Ascorbic acid content in 'Russian Orange' or 'Hergo' fruit decreased or was roughly constant during fruit development, respectively (Fig. 4). The content in ripe fruit was approximately 1 and $2 \mathrm{mg} \cdot \mathrm{g}^{-1} \mathrm{FW}$ in 'Russian Orange' and 'Hergo' fruit, respectively. These values are higher than in strawberry and kiwifruit, which are known to be rich in ascorbic acid. Ascorbic acid content in most genotypes of spp. rhamnoides in previous studies (Raffo et al., 2004; Tang, 2002), which ranges from 1 to $2.7 \mathrm{mg} \cdot \mathrm{g}^{-1} \mathrm{FW}$, was higher than in 'Russian Orange' of ssp. mongolica.

Two pathways of ascorbic acid synthesis have been proposed in fruit crops. One is the galacturonate pathway, which utilizes galacturonate from cell-wall pectin degradation, and plays a role in the increase of ascorbic acid during fruit ripening in strawberries (Agius et al., 2003). The other is the mannose/L-galactose pathway, which utilizes guanosine diphosphate-mannose and Lgalactose as intermediate metabolites (Valpuesta and Botella, 2004), and plays a role in the synthesis of ascorbic acid in kiwifruit in which ascorbic acid content is constant or decreases during fruit development (Richardson et al., 2004). The change in ascorbic acid content in sea buckthorn fruit is similar to that in kiwifruit. Thus, we determined the activity of L-GDH, which plays a key role in the mannose/L-galactose pathway (Gatzek et al., 2002; Laing et al., 2004). Sea buckthorn fruit showed high L-GDH activity (approximately $20 \mathrm{nmol} \cdot \mathrm{min}^{-1} \cdot \mathrm{mg}^{-1}$ protein) compared to several other species (less than $0.2 \mathrm{nmol} \cdot \mathrm{min}^{-1} \cdot \mathrm{mg}^{-1}$ protein in Gatzek et al., 2002). In addition, in tracer experiments, ${ }^{14} \mathrm{C}$-ascorbic acid was synthesized from $\mathrm{L}-{ }^{14} \mathrm{C}$-galactose and $\mathrm{D}^{-14} \mathrm{C}$-mannose (Fig. 5). The results suggest that the mannose/L-galactose pathway plays a role in the synthesis of ascorbic acid in sea buckthorn fruit, although the presence of the galacturonate pathway cannot be ruled out.

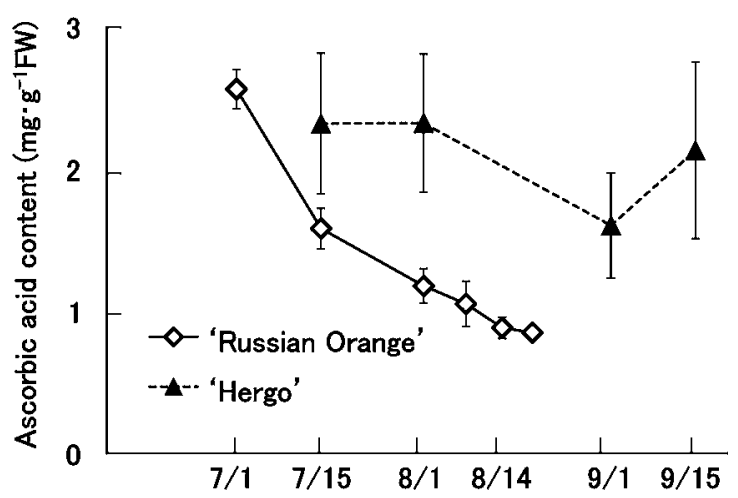

Fig. 4. Seasonal changes in ascorbic acid content in sea buckthorn fruit. Vertical bars indicate SE $(n=3)$. 

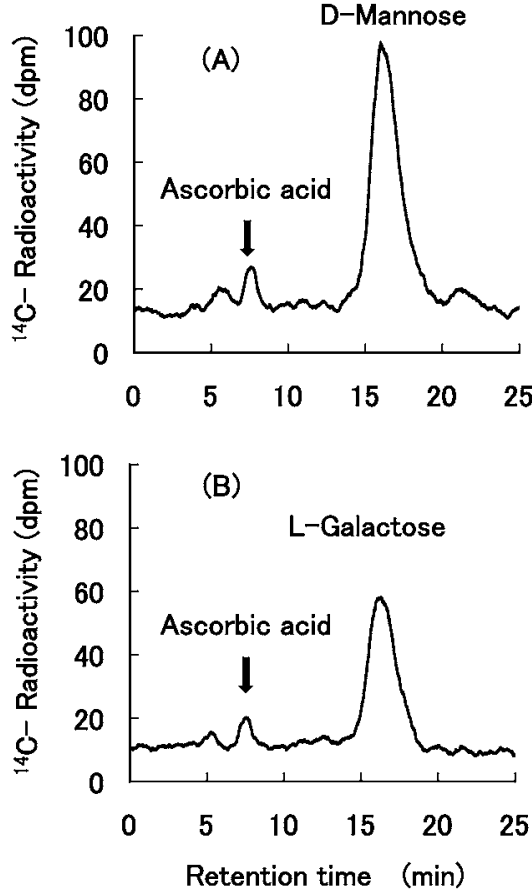

Fig. 5. Radio-HPLC chromatograms showing biosynthesis of ascorbic acid in sea buckthorn fruit. A: D- ${ }^{14} \mathrm{C}$-mannose-feeding, B: $\mathrm{L}-{ }^{14} \mathrm{C}$-galactose-feeding.

\section{Literature Cited}

Agius, F., R. Gonzalez-Lamothe, J. L. Caballero, J. Munoz-Blanco, M. A. Botella and V. Valpuesta. 2003. Engineering increased vitamin $\mathrm{C}$ levels in plants by overexpression of a Dgalacturonic acid reductase. Nature Biotech. 21: 177-181.

Albertini, M., E. Carcouet, O. Pailly, C. Gambotti, F. Luro and L. Berti. 2006. Changes in organic acids and sugars during early stages of development of acidic and acidless citrus fruit. J. Agric. Food Chem. 54: 8335-8339.

Fridman, E., F. Carrari, Y. L. Liu, A. R. Fernie and D. Zamir. 2004. Zooming in on quantative trait for tomato yield using interspecific introgressions. Science 305: 1785-1789.

Gao, X., M. Ohlander, N. Jeppsson, L. Bjork and V. Trajkovski. 2000. Changes in antioxidant effects and their relationship to phytonutrients in fruits of sea buckthorn (Hippophae rhamnoides L.) during maturation. J. Agric. Food Chem. 48: 1485-1490.

Gao, Z. and A. A. Schaffer. 1999. A novel $\alpha$-galactosidase from melon fruit with substrate preference for raffinose. Plant Physiol. 119: 979-988.

Gatzek, S., G. L. Wheeler and N. Smirnoff. 2002. Antisense suppression of L-galactose dehydrogenase in Arabidopsis thaliana provides evidence for its role in ascorbate synthesis and reveals light modulated L-galactose synthesis. Plant J. 30: 541-553.

Gentili, F. and K. Huss-Danell. 2002. Phosphorus modifies the effect of nitrogen on nodulation in split-root systems of Hippophae rhamnoides. New Phytol. 153: 53-61.

Kallio, H., B. R. Yang and P. Peippo. 2002. Effects of different origins and harvesting time on vitamin $\mathrm{C}$, tocopherols, and tocotrienols in sea buckthorn (Hippophae rhamnoides) berries. J. Agric. Food Chem. 50: 6136-6142.

Kanahama, K. 2004. Recommendations of multifunctional new berry: seaberry. [8]. Agric. and Hortic. 79: 249-255 (In
Japanese).

Kanayama, Y., M. Kogawa, M. Yamaguchi and K. Kanahama. 2005. Fructose content and the activity of fructose-related enzymes in the fruit of eating-quality peach cultivars and native-type peach cultivars. J. Japan. Soc. Hort. Sci. 74: 431436.

Kanayama, Y., W. Ohkawa, E. Chiba, K. Kato, J. Ofosu-Anim and K. Kanahama. 2008. Nutritional components and nitrogen fixation in sea buckthorn (Hippophae rhamnoides L.). Acta Hort. 806: 309-314.

Kato, K., Y. Kanayama, W. Ohkawa and K. Kanahama. 2007. Nitrogen fixation in sea buckthorn (Hippophae rhamnoides L.) root nodules and effect of nitrate on nitrogenase activity. J. Japan. Soc. Hort. Sci. 76: 185-190.

Laing, A. W., N. Frearson, S. Bulley and E. MacRae. 2004. Kiwifruit L-galactose dehydrogenase: molecular, biochemical and physiological of the enzyme. Funct. Plant Biol. 31: 10151025 .

Letchamo, W., T. Molnar and C. R. Funk. 2007. Eco-genetic variations in biological activities of sea berry (Hippophae rhamnoides). Acta Hort. 756: 229-243.

Li, C., Y. Yang, O. Junttila and E. T. Palva. 2005. Sexual differences in cold acclimation and freezing tolerance development in sea buckthorn (Hippophae rhamnoides L.) ecotypes. Plant Sci. 168: 1365-1370.

Lorence, A., B. I. Chevone, P. Mendes and C. L. Nessler. 2004. myo-Inositol oxygenase offers a possible entry point into plant ascorbate biosynthesis. Plant Physiol. 134: 1200-1205.

Matsui, H., E. Yuda and S. Nakagawa. 1979. Physiological studies on the ripening of Delaware grapes. I. Effects of the number of leaves and changes in polysaccharides or organic acids on sugar accumulation in the berries. J. Japan. Soc. Hort. Sci. 48: 9-18 (In Japanese with English abstract).

Ohkawa, W., T. L. Li, T. Seino, M. Nishiyama, Y. Kanayama and K. Kanahama. 2007. Sugar metabolic process of the ${ }^{14} \mathrm{C}$ photoassimilates on the translocation pathways of tomato plants. Tohoku J. Agric. Res. 58: 13-29.

Raffo, A., F. Paoletti and M. Antonelli. 2004. Changes in sugar, organic acid, flavonol and carotenoid composition during ripening of berries of three sea buckthorn (Hippophae rhamnoides L.) cultivars. Eur. Food Res. Technol. 219: 360 368.

Richardson, A. C., K. B. Marsh, H. L. Boldingh, A. H. Pickering, S. M. Bulley, N. J. Frearson, A. R. Ferguson, S. E. Thornber, K. M. Bolitho and E. A. Macrae. 2004. High growing temperatures reduce fruit carbohydrate and vitamin $\mathrm{C}$ in kiwifruit. Plant Cell Environ. 27: 423-435.

Rongsen, L. 2006. Biochemical characteristic of sea buckthorn (Hippophae L.). p. 98-107. In: V. Singh (ed.). Sea buckthorn (Hippophae L.), a multipurpose wonder plant. Vol. 2. Daya Publishing House, New Delhi.

Sundriyal, M. and R. C. Sundriyal. 2004. Wild edible plants of the Sikkim Himalaya: Nutritive values of selected species. Econ. Bot. 58: 286-299.

Suzuki, Y., S. Odanaka and Y. Kanayama. 2001. Fructose content and fructose-related enzyme activity during the fruit development of apple and Japanese pear. J. Japan. Soc. Hort. Sci. 70: 16-20.

Tang, X. 2002. Intrinsic change of physical and chemical properties of sea buckthorn (Hippophae rhamnoides) and implications for berry maturity and quality. J. Hort. Sci. Biotech. 77: 177 185.

Tang, X., N. Kalviainen and H. Tuorila. 2001. Sensory and hedonic characteristics of juice of sea buckthorn (Hippophae rhamnoides L.) origins and hybrids. Lebensm.-Wiss. Technol. 
34: $102-110$

Tang, X. and P. M. A. Tigerstedt. 2001. Variation of physical and chemical characters within an elite sea buckthorn (Hippophae rhamnoides L.) breeding population. Sci. Hortic. 88: 203214.

Tiitinen, K. M., B. Yang, G. G. Haraldsson, S. Jonsdottir and H. P. Kallio. 2006. Fast analysis of sugars, fruit acids, and vitamin $\mathrm{C}$ in sea buckthorn (Hippophae rhamnoides $\mathrm{L}$.) varieties. J. Agric. Food Chem. 54: 2508-2513.

Valpuesta, V. and M. A. Botella. 2004. Biosynthesis of L-ascorbic acid in plants: new pathways for an old antioxidant. Trends Plant Sci. 9: 573-577.

Wheeler, G. L., M. A. Jones and N. Smirnoff. 1998. The biosynthetic pathway of vitamin $\mathrm{C}$ in higher plants. Nature 393: $365-369$.
Yamada, K., N. Niwa, K. Shiratake and S. Yamaki. 2001. cDNA cloning of NAD-dependent sorbitol dehydrogenase from peach fruit and its expression during fruit development. J. Hort. Sci. Biotech. 76: 581-587.

Yang, B. and H. Kallio. 2002. Composition and physiological effects of sea buckthorn (Hippophae) lipids. Trends Food Sci. Technol. 13: 160-167.

Yang, Y., Y. Yao, G. Xu and C. Li. 2005. Growth and physiological responses to drought and elevated ultraviolet-B in two contrasting populations of Hippophae rhamnoides Physiol. Plant. 124: 431-440.

Yelle, S., J. D. Hewitt, N. L. Robinson, S. Damon and A. B. Bennett. 1988. Sink metabolism in tomato fruit. III. Analysis of carbohydrate assimilation in wild species. Plant Physiol. 87: 737-740. 